\title{
Environmental Conditions in a Temperate Weather Silvopastoral System vs. Natural Grassland and their Impact on Animal Beef Production
}

\author{
SM Huertas*, PE Bobadilla, HJ Bueno, D Cesar, JM Piaggio and AD Gil \\ Department of Biostatistics, Faculty of Veterinary, University of the Republic-Uruguay, Uruguay
}

Received: March 12, 2018; Published: March 26, 2018

*Corresponding author: Stella Maris Huertas, Department of Biostatistics, Faculty of Veterinary-University of the Republic, Lasplaces 1620 CP 11600 Montevideo Uruguay, Email: stellamaris32@gmail.com

\begin{abstract}
To reduce greenhouse gas emissions from ruminant production some claim that the solution is to decrease the number of beef cattle. By 2050 the world's population will reach 9.1 billion which means that we will need more food. To increase the productivity per hectare some mixed production models like silvopastoral systems which integrate forestry plantations with extensive beef production have become common. The aim is to characterize silvopastoral systems (SPS) in temperate climate evaluating some environmental conditions and comparing them to traditional natural grassland (NG) beef farming in the south of Uruguay. Preliminary results showed that SPS; generated a microclimate, had higher quality pastures, provided protection against solar radiation and strong winds for animals, mainly due to the forest component. Furthermore, animals in SPS dedicated more time grazing in summer than the animals in NG systems. Considering these results SPS appear to be non-inferior in productivity and Animal Welfare to the natural grassland based beef production. In addition SPS allow; greater stability in production (fewer economical risks), and income diversification. All of which results in an increase in the total profitability of the farm.
\end{abstract}

Keywords: Silvopastoral Systems; Natural Grassland; Animal Welfare

Abbreviations: SPS: Silvo-Pastoral Systems; NG: Natural Grassland; SPS: Silvo-Pastoral System; THI: Temperatures and Humidity Index

\section{Introduction}

In recent years greenhouse gas emissions from ruminant beef production have been considered to have a significant impact on the atmosphere's gas composition. Some may claim that the global number of ruminants should be reduced to mitigate the impact of animal production on climate change and consequently generating important social and environmental co-benefits [1]. However, by 2050 the world's population will reach 9.1 billion and the question is: How will we feed the world's population at that time? [2]. The challenge is not only to produce more, but it is also necessary to produce food safely, with healthy animals, taking care of the environment and with high animal welfare standards, hence a sustainable animal production industry. Many countries in the world base their national economies on beef cattle production, but recent increases in land prices, accelerated development of agriculture, and the need to increase the productivity per hectare have made new mixed production models to become more common, such as silvopastoral systems which integrate forestry plantations with extensive beef production. In tropical regions, especially in Latin America, these systems have proved to be beneficial for cattle production by providing protection from extreme weather and a richer environment, hence improving animal welfare. Animals in these systems benefit from; lower skin temperature 1.79 oC lower than without shade access), and use of less water and energy to maintain body temperature [3].

From the behavioural point of view, high temperatures reduce grazing times in non-shaded extensive systems, while this does not happen in silvopastoral systems [4]. Also animals show less fear in SPS because they can hide in the trees when they feel threatened [5]. Consequently, there is better human-animal interaction making the handling easier [6]. Many authors found that animals had better nutrition and growth in SPS. In some regions, the presence of nitrogen-fixing shrubs improves animal nutrition, water retention of the soil and protection against droughts. Likewise, SPS accumulate more carbon in biomass, having, hence, a good capacity to mitigate climate change [7]. Aiming to characterize silvopastoral systems in temperate climate, we evaluated some environmental conditions comparing those with traditional natural grassland beef farming in the south of Uruguay, a Latin American country.

\section{Methods}

During 2015-2016 a herd of 24 cows Bos taurus taurus (Hereford breed), 24 months old, average weight of $365 \pm 41.2 \mathrm{~kg}$. were 
randomly assigned to two paddocks of 30 hectares each, the first one was a silvopastoral system (SPS) with Eucaliptus globulus planted in 2010 with a $2 \times 2 \times 7$ design (2 lines of trees with a separation of 2 meters and 7 meters distance from the next two lines) and a tree density of 922 trees/hectare. The second one a Natural Grassland paddock. Weather conditions (air temperature and relative humidity), forest features, pasture composition and animal welfare indicators were periodically assessed for both groups according to the Welfare Quality (R)Protocol adapted to local conditions. All data was processed for statistical analysis in Stata 11 (Stata. Inc). A mixed model was used to analyse weight as a response variable. Categorical variables were compared with Fisher's exact test.

\section{Results and Discussion}

Preliminary results showed that during the summer time, temperatures and humidity index (THI) was higher in SPS than in NG, in some cases reaching alert levels, however no heat stress behaviour was observed in the animals, while in winter there were no differences, neither THI nor in animal behaviour. The animals in SPS dedicated more time grazing in summer than the animals in NG systems. The reduction of sun radiation in the SPS could account for this. Considering that in SPS the effective grazing surface is smaller than NG due to the presence of the trees, yet no significant differences were found in animal performance in both groups; however animals in SPS showed less dispersion in body weight during the study period. The botanical species diversity index was higher in SPS in comparison with NG (1.69 vs. 1.55 respectively), but in both systems botanical species of agronomic interest and of a great adaptability were presented and quantified.

Due to several aspects such as: the generation of microclimate conditions, higher quality pastures, protection against solar radiation and strong winds for animals, mainly due to the forest component the SPS appear to be non-inferior in productivity and animal welfare to the natural grassland based beef production. In addition, silvopastoral systems allow; greater stability in production (fewer economical risks), income diversification, all of which results in an increase in the total profitability of the farm. Trees are a permanent mechanism for absorbing CO2 by mitigating greenhouse gas emissions, protecting soil from erosion, favouring the recycling of nutrients, the ecological restoration of pastures, conservation of water sources, improving biodiversity and generating this environmental service that contributes to mitigate climate change.

\section{Conclusion}

SPS show promising results for beef production in temperate weather conditions. It is necessary to continue with this line of research, in temperate climates and with European breeds like the present study, since the results so far are extremely auspicious.

\section{Acknowledgement}

The authors would like to thank Uruguayan silvopatoral producer and Mrs. Emilie Akkermans for proof-reading.

\section{References}

1. Ripple W, Smith P, Haberl H, Montzka S, McAlpine C, et al. (2013) Ruminants, climate change and climate policy. Nature Climate Change $4(1): 2-5$.

2. Alexandratos N, Bruinsma J (2012) World agriculture towards 2030/2050: the 2012 revision. Agricultural Development Economics Division Food and Agriculture Organization of the United Nations, Rome.

3. W Barragán, La Mahecha, Yasmin Socorro (2015) Physiologicalmetabolic variables of heat stress in cows under silvopastoralism and treeless grassland. Agronomía Mesoam 26(2): 211-223.

4. Améndola L, Solorio FJ, González-Rebeles C, Galindo F (2013) Behavioural indicators of cattle welfare in silvopastoral systems in the tropics of México. Proceedings of $47^{\text {th }}$ Congress of International Society for Applied Ethology, Florianópolis. Wageningen Academic Publishers, Wageningen.

5. Ocampo A, Cardozo A, Tarazona A, Ceballos M, Murgueitio E (2011) Participatory research on Animal Welfare and Behavior in the Tropics of America: Opportunities for New Applied Knowledge. Revista Colombiana de Ciencias Pecuarias 3(24).

6. Mancera AK, Galindo F (2011) Evaluation of some sustainability indicators in extensive bovine stockbreeding systems in the state of Veracruz. VI Reunión Nacional de Innovación Forestal, León Guanajauato, México, p. 31.

7. Broom DM, Galindo FA, Murgueitio E (2013) Sustainable, efficient livestock production with high biodiversity and good welfare for animals. Proc R Soc B 280: 2013-2025.
This work is licensed under Creative Commons Attribution 4.0 License

Submission Link: https://biomedres.us/submit-manuscript.php

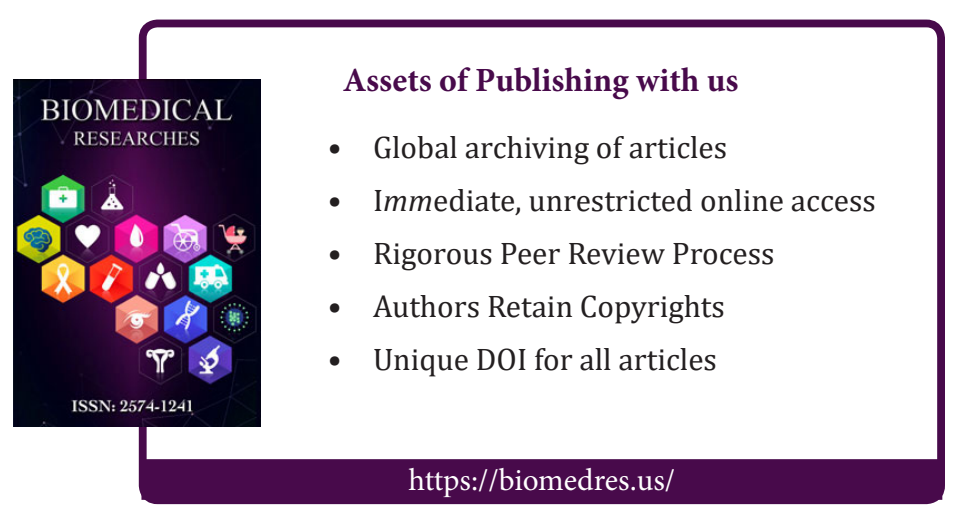

